\title{
CORRECTION
}

\section{Correction to: Glutamate triggers the expression of functional ionotropic and metabotropic glutamate receptors in mast cells}

Md Abdul Alim ${ }^{1,2}$, Mirjana Grujic ${ }^{2}$, Paul W. Ackermann ${ }^{3}$, Per Kristiansson ${ }^{1}$, Parmis Blomgran ${ }^{4}$, Pernilla Eliasson $^{4}$, Magnus Peterson $^{1,5}$ and $^{2}$ Gunnar Pejler (iD) 2,6

Cellular \& Molecular Immunology (2020) 17:1117; https://doi.org/10.1038/s41423-020-00543-1

Correction to: Cellular and Molecular Immunology https://doi.org/ 10.1038/s41423-020-0421-z, published online 20 April 2020

The authors have agreed to add Parmis Blomgran (Linköping University, Department of Orthopedics and Sports Medicine, Linkoping, Sweden) as co-author of this study. The updated order of authors will be: Md Abdul Alim, Mirjana Grujic, Paul W Ackerman, Per Kristiansson, Parmis Blomgran, Pernilla Eliasson, Magnus Peterson, Gunnar Pejler.

${ }^{1}$ Department of Public Health and Caring Sciences, General Medicine and Preventive Medicine, Uppsala University, Uppsala, Sweden
${ }^{2}$ Department of Medical Biochemistry and Microbiology, Uppsala University, Uppsala, Sweden

${ }^{3}$ Department of Molecular Medicine and Surgery, Karolinska Institutet, Stockholm, Sweden

${ }^{4}$ Department of Orthopedics and Sports Medicine, Linköping University, Linkoping, Sweden

${ }^{5}$ Academic Primary Health Care, Region Uppsala, Uppsala, Sweden

${ }^{6}$ Department of Anatomy, Physiology and Biochemistry, Swedish University of Agricultural Sciences, Uppsala, Sweden

\footnotetext{
${ }^{1}$ Department of Public Health and Caring Sciences, General Medicine and Preventive Medicine, Uppsala University, Uppsala, Sweden; ${ }^{2}$ Department of Medical Biochemistry and Microbiology, Uppsala University, Uppsala, Sweden; ${ }^{3}$ Department of Molecular Medicine and Surgery, Karolinska Institutet, Stockholm, Sweden; ${ }^{4}$ Department of Orthopedics and Sports Medicine, Linköping University, Linkoping, Sweden; ${ }^{5}$ Academic Primary Health Care, Region Uppsala, Uppsala, Sweden and ${ }^{6}$ Department of Anatomy, Physiology and Biochemistry, Swedish University of Agricultural Sciences, Uppsala, Sweden

Correspondence: Magnus Peterson (magnus.peterson@pubcare.uu.se) or Gunnar Pejler (gunnar.pejler@imbim.uu.se)
}

Published online: 3 September 2020 